\title{
Feasibility of a community-based cancer awareness initiative: views of those delivering and managing the intervention
}

\author{
Julia Mueller $^{1,2}$ (D) Emily Parry-Harries ${ }^{1,3} \cdot$ Gary Clough $^{1} \cdot$ Arpana Verma $^{1}$
}

Received: 15 October 2020 / Accepted: 27 April 2021 / Published online: 21 May 2021

(C) The Author(s) 2021

\begin{abstract}
Aim Many people delay presenting to health services with cancer symptoms due to lack of awareness, particularly in areas of high socio-economic deprivation. A three-year community-based intervention was launched in Northwest England to improve public awareness of cancer symptoms. In this study, we aimed to evaluate this intervention by exploring the views of those involved in its management and delivery.

Methods Ten semi-structured interviews were conducted with volunteers as well as members of the project management and steering group. Interviews were analysed qualitatively using thematic analysis.

Results Participants felt they succeeded in raising awareness, influencing behaviour, connecting with local communities and engaging with vulnerable people. Participants perceived some weaknesses in the delivery of the intervention, including limited engagement of stakeholders, particularly general practitioners (GPs), and socially excluded groups.

Conclusions Future public health interventions should pay particular attention to engagement of socially excluded individuals who do not interact with community events or groups, and to the engagement of stakeholders in early planning stages of the intervention. This should involve a specific GP engagement plan.
\end{abstract}

Keywords Cancer $\cdot$ Health promotion $\cdot$ Public health $\cdot$ Qualitative research $\cdot$ Community-based

\section{Introduction}

Cancer survival rates in the UK are below the European average, and survival rates are lower than in other European countries with comparable per capita total national expenditure for health (Berrino et al. 2009; De Angelis et al. 2014). Research indicates that poor cancer survival in the UK is attributable to delays in diagnosis, with an estimated 5000-10,000 annual cancer deaths occurring within 5 years of diagnosis that could be avoided through earlier diagnosis (Richards 2009).

To reduce the time between onset of symptoms and presentation to healthcare services, it is important to increase

Julia Mueller

julia.mueller@mrc-epid.cam.ac.uk

1 Division of Population Health, Health Services Research and Primary Care, University of Manchester, Manchester Academic Health Sciences Centre, Manchester, UK

2 MRC Epidemiology Unit, University of Cambridge, Cambridge, UK

3 Kirklees Council, Huddersfield, UK public awareness of signs and symptoms of cancer. Awareness of many cancer symptoms and risk factors is low among the UK population (Niksic et al. 2015). The majority of cancers occur in people aged 50-74 years, with breast, bowel and lung cancer being among the most commonly diagnosed cancer types in this age category (Møller et al. 2009; Thomson and Forman 2009). Thus, targeting public awareness of signs and symptoms of these three cancer types could make an important contribution to reducing delays to diagnosis.

Individuals living in areas of high socio-economic deprivation are more susceptible to delays to diagnosis (Ellis et al. 2009; Marmot 2010). Deprivation has also been linked to increased exposure to predisposing factors, including poor lifestyle choices, unemployment, low education levels and low housing quality (Marmot 2010). Other groups that are vulnerable to delays to cancer diagnosis include, for example, ethnic minority groups and people with learning disabilities (Alborz et al. 2005; Forbes et al. 2011). Henceforth, these groups will be referred to as 'vulnerable groups'.

Programmes that involve community lay health volunteers in partnership with primary care and other professionals have 
delivered positive results, improving the early diagnosis of cancer symptoms in disadvantaged communities by leading work on awareness-raising and the promotion of earlier presentation of cancer symptoms (Lyon et al. 2009). The 'Let's be clear, get it checked!' initiative was a community-based intervention to raise awareness of cancer symptoms and promote timely help-seeking which ran over a period of three years in Manchester and Tameside \& Glossop in North West England.

While outcomes of the effectiveness of interventions are important, process evaluations of the delivery of interventions are equally crucial (Steckler and Linnan 2002). An instrumental step in conducting process evaluations is incorporating views from those involved in the delivery and management of the intervention (Craig et al. 2008). This helps to determine whether the intervention was delivered as intended, and to streamline the delivery of future interventions. This can provide useful learning and insights for those planning and designing interventions. Qualitative research is well suited to explore, in detail, the perceptions and subjective experiences of individuals. To our knowledge there is, to date, no published study which evaluates a community-based cancer awareness intervention using insights from those involved in the delivery and management.

The aim of this study was to qualitatively evaluate the community-based cancer awareness raising programme 'Let's be clear, get it checked!' in terms of the engagement of relevant groups, from the point of view of those delivering the intervention (volunteers) or participating in the steering group.

\section{Methods}

\section{Intervention}

Using a community-based approach, a three-year intervention titled 'Let's be clear, get it checked!' was implemented in Manchester and Tameside \& Glossop in North West England. The main aim of the intervention was to target vulnerable individuals from areas of high socio-economic deprivation by recruiting and training volunteers from the target population to deliver the intervention. The volunteers engaged with the public and provided information on bowel, lung and breast cancer to promote the attendance at primary care at an early stage of cancer symptoms.

The intervention ran from early 2011 until March 2015. In total, 78 volunteers were recruited through leaflets, approaching staff in existing services, and word-of-mouth, with particular focus on recruiting from areas of high deprivation. The recruitment of volunteers also followed the snowballing method, whereby volunteers would provide cancer information within their own communities with the intention of recruiting further participants for training. Volunteers were not required to hold any formal qualifications. Training sessions ran over two days and included information on the signs and symptoms of the three cancer types and guidance in the use of public engagement games. The volunteers engaged with the public in group meetings (e.g. community groups), one-to-one sessions (usually run within group sessions) and stalls at community events. Settings for the delivery included community centres, supermarkets, markets, fairs, pubs, social clubs, leisure centres and churches. For the group meetings, project coordinators initiated contact with established community groups (or companies and community groups contacted the study coordinators to set up group sessions after having heard of the intervention e.g. via stalls at events or other advertisements) and volunteers then arranged to attend one of their pre-arranged meetings to deliver the intervention. Intervention delivery included leaflets (e.g. Macmillan, Be Clear on Cancer), PowerPoint presentations and games (e.g. with signs and symptoms cards). At community events, volunteers set up stalls which included posters and leaflets. The intervention team researched upcoming suitable events and made arrangements for stalls in advance. Intervention attendees were always given the opportunity to ask questions. As such, the intervention delivery could vary from a few minutes to a few hours.

\section{Recruitment and design}

One-to-one semi-structured interviews were undertaken with volunteers who had delivered the intervention and members of the steering group. The project steering group comprised representatives from the Christie NHS Foundation Trust, Macmillan Cancer Support, and Manchester and Tameside \& Glossop local authorities. The steering group met regularly to obtain project updates. Duties of the steering group included monitoring the progress and reach of the project, approving study/intervention materials and ensuring the project met its targets.

Interviews were conducted in a quiet room on hospital or university premises, depending on participants' preferences. The interviewer (GC) was a member of the evaluation team and was, as such, known to the interviewees but independent of the delivery and management of the intervention. Interviews were approximately $20-30 \mathrm{~min}$ in length. Each interview was audio-recorded and transcribed verbatim. Participants were recruited using convenience sampling. Initially, the evaluation team approached all members of the project management and coordination group and five members agreed to participate. The evaluation team then sought an equal number of volunteers. The project coordinators invited volunteers from their intervention zones to participate, and the first five who consented to take part were included in the study. Thus, five interviews were conducted with members 
of the steering group and five interviews with volunteers (10 interviews in total). The interviewees discussed the impact on the identified population, perceived behaviour change achieved, and their experience of working on a communitybased health improvement project (for the full interview schedule, see Appendix 1). Informed written consent was obtained from all participants. Ethical approval was granted by North West Cheshire REC.

\section{Analysis}

A thematic approach was used to analyse interview transcripts (Braun and Clarke 2006). Transcripts were read several times to achieve familiarisation with the data. Interview questions were used as a priori themes to group the data by summarising transcripts in matrices according to interview questions, which facilitated comparisons across participants. Key points and issues were identified in the matrices, highlighted manually and coded descriptively. Descriptive codes were then categorised to create conceptual themes. Two researchers independently reviewed and coded the transcripts. Conflicts were discussed until consensus was reached. Coding continued until no new themes emerged.

\section{Results}

Four central themes were identified and are presented below.

\section{Raising awareness}

Interviewees voiced a positive opinion regarding their perception of the effectiveness of the intervention in raising cancer awareness and promoting early presentation to health services.

“... because we target a lot of different groups [...] and personally I've probably seen hundreds of people by now with all the different events that I've done, [...] it's knowing that you've had that contact with people ..." [Subject H, volunteer]

Interviewees also reported receiving positive feedback from the participants in the intervention, strengthening their view that the intervention was effective.

"I believe that it's very, very effective and everyone I speak to with feedback that we get, saying how grateful they are that they got that information" [Subject D, volunteer]

Additionally, the use of community-based, local volunteers was felt to enhance the intervention's ability to influence people's behaviour.
"I think it's been a really effective approach because you're using volunteers, people that are in the community, that know that community, [...] and so by them having that knowledge, that respect, that credibility, then you'll get into those people and trying to enhance their awareness of cancer [...] to try and improve detecting cancer earlier and stop people sitting on symptoms. " [Subject K, steering group member]

It should be noted that interviewees were unable to comment on the effectiveness of the intervention in changing behaviour, because they did not follow up whether those receiving the intervention subsequently sought help.

"We're simply giving the presentation and, and giving as much encouragement as we can, and the only thing as I mentioned is the generally ethos I've mentioned to you before, which is that a number of people at the end of the presentation will say "I think I better get that checked", or "I will try and encourage so and so to get that checked" so you, you have not got any substantive evidence, you have a kind of ethos that you have made people think and, and you made people think without frightening them." [Subject B, volunteer]

\section{Connecting with communities}

Interviewees discussed strengths of delivering the intervention in established community settings where people tend to congregate such as fairs, pubs and supermarkets. All interviewees viewed this approach positively. A main advantage identified by interviewees was that this allowed volunteers to efficiently disseminate information to a wide audience which would have otherwise been difficult to gather together.

“...we engage with you know 300 to 400 people just in one day....in a hard-to-reach area, which, you know, I think it highlights, you know, how well this project does when you're in key communities. " [Subject F, steering group member]

While reaching large audiences was considered important, interviewees also felt this approach allowed volunteers to connect with individuals on a personal level.

"I like the personal ones where we'll visit sheltered housing and we might have ten people at the table, [...] and if you've got people sat around the table you can sort of, you can speak to them." [Subject D, volunteer] 
Delivering the intervention in these settings also enabled recruitment of further volunteers for the project, increasing the number of local volunteers who had "good knowledge and real understanding of what sort of things people do shy away from and want" [Subject E, steering group member].

Interviewees reported that attending community events enabled them to further network with other community groups and organisations, opening opportunities for the delivery of the intervention in further settings and venues and thus widening the audience.

One interviewee commented on the informality of the community-based approach and suggested that this facilitated communication with people who might otherwise have been unwilling to discuss cancer topics.

"... what you might call gimmicky type stuff, bowel bingo is one that works particularly well and the inflatable colon... but those sorts of things have, have demonstrated very good engagement. [...] It gets across at people that actually if they just want to play the game, they can just play the game..... and it's quite clear from the branding that this is about cancer if they want to start talking about cancer." [Subject G, steering group member]

\section{Identifying and engaging with vulnerable groups}

The majority of interviewees reportedly felt the intervention was successful in engaging vulnerable groups. Having materials and volunteers who could communicate with minority groups in their own languages was seen to remove barriers and help get the message across more effectively.

Steering group members based their assessment on their overview of the diversity of volunteers and groups involved in the intervention.

"We've got quite a range of volunteers from different ethnicities and that's been useful, so one of our volunteers is originally from Malawi, but her parents were from India so she did some session with some older Asian's women's group and they kind of pushed her into speaking in Punjabi. But I think that probably broke down a few barriers than if it had just been me delivering it. " [Subject C, Steering group member]

Volunteers reported specific groups and people they had engaged with.

"I've been involved in a session with one of the groups downstairs in Age UK where [...] it's like a mental health group, so they come regularly in here, so I've definitely been to that [...], and then in a couple of weeks I'm meeting a women's group, BME women's group, so that's another..." [Subject $H$, volunteer]

The delivery of the intervention in community-based settings was perceived to contribute to the engagement of vulnerable groups, as areas and community initiatives were chosen specifically to target health inequalities.

“... yes we've definitely improved the access, [...] we've done lots of work with BME [Black and Minority Ethnic] communities, we've done work with people with mental health problems, we've done work with people from socially deprived, you know, looking for employment opportunities. " [Steering group member]

Volunteers, who delivered the intervention, perceived some barriers to engaging socially excluded groups. It was pointed out that the intervention was tied to established community settings and groups; thus inclusion of people who do not visit any of these settings was not possible.

“... we've gone to various presentations, interventions we've made, the community groups, the church groups, the social groups [...] but invariably if there are people who will not leave their homes and will not join those... they are the most vulnerable and obviously as you will know very hard-to-reach." [Subject B, volunteer]

\section{Engagement of stakeholders}

Stakeholders in the intervention included patients, carers, members of the funding and administrator bodies, professionals in the field of cancer awareness, members of cancer charities, university academics and health professionals. Steering group members commented on the engagement of stakeholders during the development stages of the project; volunteers were recruited after the planning stages and therefore did not comment on this aspect.

Interviewees commented that it seemed the development of the project was based mainly on national statistics, with relatively little engagement of the target communities in the planning stages. Interviewees suggested more stakeholder involvement should have taken place in the development stages, especially by involving service users like patients and carers.

"... the importance of co-creation of developments with the service user, patient or carer, rather than 'this is what we're going to do, what do you think about it?' It's a totally different thing and it takes a long, long time, [...] That could have been done a lot better....really understood and got in some community voices." [Subject K, steering group member] 
Interviewees commented specifically on difficulties in engaging General Practitioners (GPs) in the planning stages of the project. Although GPs were not directly involved in the delivery of the intervention, a main aim of the intervention was to encourage members of the public to attend primary care with symptoms and warning signs and the support and endorsement of the project by GPs was therefore of relevance.

\begin{abstract}
"We encouraged them to be engaged but they're not as engaged as we'd like them to be. I think that's not due to the fault of the GPs for example but it's just due to the circumstances and time and pressures on them as well so I think it's just very difficult.." [Subject $\mathrm{K}$, steering group member]

"...from my end I think we only did, we only touched upon it but I also think where we fell down was we didn't have a specific GP engagement plan [...] there did need to be a specific GP engagement plan, there did need to be a specific whether the project team are targeting it, if so we could have got on with it straight away." [Subject $\mathrm{F}$, steering group member]
\end{abstract}

\section{Discussion}

The aim of this study was to qualitatively evaluate a communitybased cancer awareness intervention in terms of the engagement of relevant groups by exploring the views of those involved in the management and delivery of the intervention. This constitutes a crucial step in evaluating the feasibility of the intervention (Craig et al. 2008). Our findings show that volunteers delivering the intervention and members of the steering group believed the intervention was successful in engaging vulnerable groups, though some barriers remained.

\section{Perceived strengths of the intervention}

Both volunteers and steering group members perceived the intervention as effective, though they based their evaluations on different aspects. Steering group members had, through their role in the project management, obtained an overview of the intervention, including the different volunteers and strategies it incorporated, the number of people that were engaged with per day and the number and diversity of organisations networked with. Volunteers, on the other hand, based their appraisals on specific experiences they had personally made in engaging with members of the public. This unique combination of insights provides novel support for the effectiveness of community-based approaches.

Volunteers and steering group members felt that targeting areas and groups known to be vulnerable to health inequalities resulted in enhanced engagement. Previous research confirms this finding, demonstrating the value of community interventions in engaging minority groups (Kreps and Sparks 2008) and stressing the importance of collaborating with established community organisations to integrate vulnerable groups (Flanagan and Hancock 2010).

Interviews showed that the volunteers involved in this intervention had valuable knowledge and skills, such as speaking minority languages, that helped them connect and engage with vulnerable groups. This is consistent with previous research that has shown that lay health workers delivering public health interventions are successful in engaging participants by having cultural understanding and relevant experiences (South et al. 2013).

Additionally, research has shown that immigrant populations are particularly vulnerable to health inequalities, which is aggravated by language and health literacy barriers (Kreps and Sparks 2008). Our findings indicate that this intervention provided learning material, games and strategies that addressed these barriers.

\section{Perceived weaknesses and barriers of the intervention}

While the findings demonstrate some success in the engagement of vulnerable groups, barriers to engaging some groups were identified. Volunteers delivering the intervention perceived barriers to integrating particularly those people who do not participate in community events. This may include for example drug users, refugees and homeless people, as well as those who are socially isolated or do not generally associate with other members of the community (Flanagan and Hancock 2010). These groups are particularly vulnerable to health inequalities (Health and Safety Executive 2004). The barriers to intervention engagement of socially excluded groups are numerous, and no single solution exists to solve this complex problem. A comprehensive approach involving an array of strategies is likely needed (Bonevski et al. 2014). This in turn involves considerable investment of resources, in terms of both time (to allow for early, long-term planning and to build relevant relationships) and financial resources (e.g. creation of culturally tailored materials, additional staff training, additional staff time for outreach activities). Those developing interventions (and wider stakeholders such as funders) should therefore ensure timelines and budgets are sufficient to allow for these increased resources (Bonevski et al. 2014). Additionally, interventions should allow tailoring to the specific needs of different sub-groups. For example, men may prefer structured programmes with defined tangible outcomes (Carroll et al. 2014).

A further weakness of the intervention identified in this study was stakeholder involvement during the planning stages of the project. Steering group members felt that higher engagement of stakeholders during the development of the 
intervention, especially patients, carers and members of the public, could have increased the effectiveness of the intervention by ensuring enhanced tailoring to the specific needs of the areas and populations it targeted. Consultation of stakeholders can help facilitate development of comprehensive cancer prevention strategies (Abed et al. 2000). Moreover, co-producing interventions together with stakeholders can help tailor interventions to local contexts and target populations, thereby enhancing the likelihood of successful implementation and 'buyin' to the intervention (Hawkins et al. 2017). However, previous literature has highlighted that co-production can be impeded by the additional time and resources needed, competing priorities and conflicting views between stakeholders (Hawkins et al. 2017).

Another perceived barrier to implementation of the intervention was low engagement of GPs. Past studies have highlighted the difficulty in engaging primary care facilities in health promotion (Larme and Pugh 1998). There are a number of ways in which GPs can be involved in health promotion activities, such as providing information material to patients during consultations, encouraging certain health activities (including screening), lobbying politicians, opportunistic screening and supporting local outreach work (Simon 2012; Emery et al. 2014).

\section{Recommendations and future work}

Our study highlights the importance of stakeholder engagement during planning stages of community-based interventions. Focus groups and interviews with stakeholders during the planning of projects could help identify needs, resources and priorities within the targeted areas prior to intervention development and implementation. Furthermore, research is needed to obtain a comprehensive understanding of the barriers to GP involvement, and interventions need a clear GP engagement strategy to enhance their delivery. Finally, future community-based interventions need to pay particular attention to the engagement of socially excluded individuals who do not participate in community groups and do not visit community settings.

\section{Conclusions}

Overall, the findings of this study demonstrate the feasibility of the intervention and show that the intervention team felt able to engage with members of the community and deliver health information in an adequate format. The communitybased approach of the intervention was perceived as conducive and supportive for the intervention's aims. Some challenges were mentioned that made delivery of the intervention difficult, such as limited engagement of stakeholders, particularly primary care, and engagement of socially excluded groups and individuals. Future research and public health efforts should focus on systematically identifying and addressing barriers to stakeholder engagement during the development and delivery of health promotion initiatives.

Supplementary Information The online version contains supplementary material available at https://doi.org/10.1007/s10389-021-01581-3.

Acknowledgements We thank the participants who took part in this study. This study was funded by Macmillan Cancer Support and administered through The Christie NHS Foundation Trust.

Authors' contributions AV, GC and EPH designed the study. GC and EPH collected the data. JM, GC and EPH analysed the data. EPH and JM wrote the first draft of the manuscript, and all authors revised it critically and approved the final version to be published.

Funding This study was funded by Macmillan Cancer Support and the Christie Hospital NHS Foundation Trust.

Availability of data and material Not applicable.

Code availability Not applicable.

\section{Declarations}

Conflict of interest None declared.

Ethics approval Ethical approval was granted by North West Cheshire REC.

Consent to participate Informed written consent was obtained from all study participants.

Consent for publication Not applicable.

Open Access This article is licensed under a Creative Commons Attribution 4.0 International License, which permits use, sharing, adaptation, distribution and reproduction in any medium or format, as long as you give appropriate credit to the original author(s) and the source, provide a link to the Creative Commons licence, and indicate if changes were made. The images or other third party material in this article are included in the article's Creative Commons licence, unless indicated otherwise in a credit line to the material. If material is not included in the article's Creative Commons licence and your intended use is not permitted by statutory regulation or exceeds the permitted use, you will need to obtain permission directly from the copyright holder. To view a copy of this licence, visit http://creativecommons.org/licenses/by/4.0/.

\section{References}

Abed J, Reilley B, Butler MO et al (2000) Developing a framework for comprehensive cancer prevention and control in the United States: 
an initiative of the Centers for Disease Control and Prevention. J Public Heal Manag Pract 6:67-78. https://doi.org/10.1097/ 00124784-200006020-00011

Alborz A, McNally R, Glendinning C (2005) Access to health care for people with learning disabilities in the UK: mapping the issues and reviewing the evidence. J Health Serv Res Policy 10:173-182. https://doi.org/10.1258/1355819054338997

Berrino F, Verdecchia A, Lutz JM et al (2009) Comparative cancer survival information in Europe. Eur J Cancer 45:901-908. https://doi. org/10.1016/j.ejca.2009.01.018

Bonevski B, Randell M, Paul C et al (2014) Reaching the hard-to-reach: a systematic review of strategies for improving health and medical research with socially disadvantaged groups. BMC Med Res Methodol 14:1-29. https://doi.org/10.1186/1471-2288-14-42

Braun V, Clarke V (2006) Using thematic analysis in psychology. Qual Res Psychol 3:77-101. https://doi.org/10.1191/1478088706qp063oa

Carroll P, Kirwan L, Lambe B (2014) Engaging 'hard to reach' men in community based health promotions. Int J Heal Promot Educ 52: 120-130. https://doi.org/10.1080/14635240.2013.876185

Craig P, Dieppe P, Macintyre S et al (2008) Developing and evaluating complex interventions: the new Medical Research Council guidance. BMJ 337:a1655. https://doi.org/10.1136/bmj.a1655

De Angelis R, Sant M, Coleman MP et al (2014) Cancer survival in Europe 1999-2007 by country and age: results of EUROCARE5-a population-based study. Lancet Oncol 15:23-34. https://doi. org/10.1016/S1470-2045(13)70546-1

Ellis L, Rachet B, Shah A et al (2009) Trends in cancer survival in Spearhead Primary Care Trusts in England,1998-2004. Health Stat Q 41:7-12. https://doi.org/10.1057/hsq.2009.3

Emery JD, Shaw K, Williams B et al (2014) The role of primary care in early detection and follow-up of cancer. Nat Rev Clin Oncol 11:38 48. https://doi.org/10.1038/nrclinonc.2013.212

Flanagan SM, Hancock B (2010) Reaching the hard to reach - lessons learned from the VCS (voluntary and community sector). A qualitative study. BMC Health Serv Res 10:92. https://doi.org/10.1186/ 1472-6963-10-92

Forbes LJL, Atkins L, Thurnham A et al (2011) Breast cancer awareness and barriers to symptomatic presentation among women from different ethnic groups in East London. Br J Cancer 105:1474-1479

Hawkins J, Madden K, Fletcher A et al (2017) Development of a framework for the co-production and prototyping of public health interventions. BMC Public Health 17:689. https://doi.org/10.1186/ s12889-017-4695-8
Health and Safety Executive (2004) Successful interventions with hard to reach groups

Kreps GL, Sparks L (2008) Meeting the health literacy needs of immigrant populations. Patient Educ Couns 71:328-332. https://doi.org/ 10.1016/j.pec.2008.03.001

Larme AC, Pugh JA (1998) Attitudes of primary care providers toward diabetes: barriers to guideline implementation. Diabetes Care 21: 1391-1396. https://doi.org/10.2337/diacare.21.9.1391

Lyon D, Knowles J, Slater B, Kennedy R (2009) Improving the early presentation of cancer symptoms in disadvantaged communities: putting local people in control. Br J Cancer 101(Suppl):S49-S54. https://doi.org/10.1038/sj.bjc.6605390

Marmot M (2010) Fair society, healthy lives: strategic review of health inequalities in England post-2010. London

Møller H, Linklater KM, Robinson D (2009) A visual summary of the EUROCARE-4 results: a UK perspective. Br J Cancer 101(Suppl): S110-S114. https://doi.org/10.1038/sj.bjc.6605400

Niksic M, Rachet B, Warburton FG et al (2015) Cancer symptom awareness and barriers to symptomatic presentation in England-are we clear on cancer? Br J Cancer 113:533-542. https://doi.org/10.1038/ bjc. 2015.164

Richards MA (2009) The size of the prize for earlier diagnosis of cancer in England. Br J Cancer 101:125-129. https://doi.org/10.1038/sj. bjc. 6605402

Simon C (2012) Health promotion in primary care. InnovAiT 5:725-731. https://doi.org/10.1093/innovait/ins117

South J, Meah A, Bagnall AM, Jones R (2013) Dimensions of lay health worker programmes: results of a scoping study and production of a descriptive framework. Glob Health Promot 20:5-15. https://doi. org/10.1177/1757975912464248

Steckler A, Linnan L (2002) Process evaluation for public health interventions and research (medical sciences), 1st edn. John Wiley \& Sons, Ltd, San Francisco

Thomson CS, Forman D (2009) Cancer survival in England and the influence of early diagnosis: what can we learn from recent EUROCARE results? Br J Cancer 101(Suppl):S102-S109 https:// doi.org/10.1038/sj.bjc.6605399

Publisher's note Springer Nature remains neutral with regard to jurisdictional claims in published maps and institutional affiliations. 